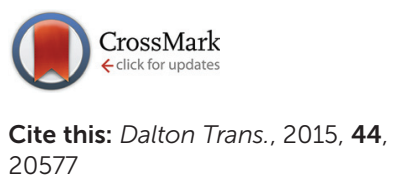

20577

Received 1st October 2015,

Accepted 26th October 2015

DOI: $10.1039 / c 5 d t 03835 a$

www.rsc.org/dalton

\title{
Highly nucleophilic dipropanolamine chelated boron reagents for aryl-transmetallation to iron complexes $\dagger$
}

\author{
Jay J. Dunsford, Ewan R. Clark and Michael J. Ingleson*
}

\begin{abstract}
New aryl- and heteroarylboronate esters chelated by dipropanolamine are synthesised directly from boronic acids. The corresponding anionic borates are readily accessible by deprotonation and demonstrate an increase in hydrocarbyl nucleophilicity in comparison to other common borates. The new borates proved competent for magnesium or zinc additive-free, direct boron-to-iron hydrocarbyl transmetallations with well-defined iron(॥) (pre)catalysts. The application of the new borate reagents in representative $\mathrm{Csp}^{2}-\mathrm{Csp}^{3}$ cross-coupling led to almost exclusive homocoupling unless coupling is performed in the presence of a zinc additive.
\end{abstract}

\section{Introduction}

Nucleophilic organoboron compounds are crucial in modern synthesis, particularly in transition metal catalysed carboncarbon bond formation such as the synthetically ubiquitous Suzuki-Miyaura (SM) reaction. ${ }^{1-3}$ In the SM reaction the transfer of a hydrocarbyl group from boron to a transition metal is an essential step and one that has been extensively studied for palladium systems. ${ }^{4}$ Extending the SM reaction from palladium catalysis to base metal catalysts, with a particular emphasis on iron is important to reduce our current reliance upon expensive and toxic palladium catalysts. ${ }^{5,6}$ The unique reaction pathways accessible to iron catalysis ${ }^{6-10}$ (both one and two electron manifolds) also represent a considerable driving force for the advancement of this area. Recent advances in iron catalysed SM type cross-coupling have been significant, particularly in the employment of anionic borate nucleophiles, $\left[\mathrm{B}(\mathrm{Ar})_{4}\right]^{-11,12}\left[\mathrm{RB}(\mathrm{pin})\left({ }^{t} \mathrm{Bu}\right)\right]^{-}$(pin = pinacolato, $\mathrm{R}=$ aryl $/$ alkenyl $)^{13,14}$ and $\left[\mathrm{R}^{\prime} \mathrm{BR}_{3}\right]^{-}\left(\mathrm{R}^{\prime}=\right.$ Alkyl or Aryl $) .{ }^{15}$ However, in contrast to $\mathrm{Pd}$ catalysed $\mathrm{SM}$, where $\mathrm{ArB}(\mathrm{OR})_{2}$ and a range of bases in aqueous/ether media readily effect boron to Pd transmetallation, transmetallation to iron is more challenging and analogous conditions do not effect hydrocarbyl transfer. Instead boron to iron transmetallation requires organometallic activating agents (e.g. ${ }^{t} \mathrm{BuLi}$ or ArMgX) in examples employing pinacolboronate esters or triorganoboranes. ${ }^{13-15}$ Furthermore,

School of Chemistry, University of Manchester, M13 9PL, UK.

E-mail: Michael.ingleson@manchester.ac.uk

$\dagger$ Electronic supplementary information (ESI) available: Full experimental, computational and X-ray crystallographic details and all relevant NMR spectra. CCDC 1010524, 1010526 and 1058782. For ESI and crystallographic data in CIF or other electronic format see DOI: 10.1039/c5dt03835a additives such as $\mathrm{MgBr}_{2}, \mathrm{ZnCl}_{2}$ or $\mathrm{Zn}(\mathrm{Ar})_{2}$ are required for good heterocoupling yields in the Fe catalysed SM reaction, with additive free systems providing inferior heterocoupling outcomes. ${ }^{14}$ These additives are proposed to facilitate hydrocarbyl transmetallation, although their specific role(s) in this process have yet to be defined. Hydrocarbyl transmetallation from boron-to-iron ${ }^{16}$ employing modular boronate reagents that are readily accessible, particularly from the widely available boronic acids, and are activated for transmetallation using simple bases (e.g., Group I M[OR] salts) would be attractive for iron catalysed SM protocols. ${ }^{17}$ Herein, we describe our efforts toward this goal, principally through the design of highly nucleophilic borate reagents and their application in boron-to-iron hydrocarbyl transmetallation.

\section{Results and discussion}

Our recent investigations on boron-to-iron hydrocarbyl transmetallation, employing $\left[\mathrm{Fe}(\mathrm{NHC})_{2} \mathrm{X}_{2}\right](\mathrm{NHC}=N$-heterocyclic carbene, $\mathrm{X}=\mathrm{Cl}$ or $\mathrm{OMe}$ ) systems with arylborate nucleophiles afforded key observations of significance to our current investigation. ${ }^{18}$ Specifically, that alkoxide transfer from arylborates of the general formulae, $[\mathrm{ArB}(\mathrm{eg})(\mathrm{OMe})]^{-}(\mathrm{eg}=$ ethylene glycolato $)$ occurs in preference to aryl transfer (Fig. 1). Considering this, we set out to design a new class of highly nucleophilic borates that incorporate tethered, trianionic ligands and are accessible from boronic acids and Group I M[OR] salts, with the intention of facilitating hydrocarbyl transfer in preference to alkoxide transfer (Fig. 1).

Borate reagents incorporating tethered, trianionic ligands are known, ${ }^{19}$ with the triolborates particularly noteworthy, ${ }^{20}$ 


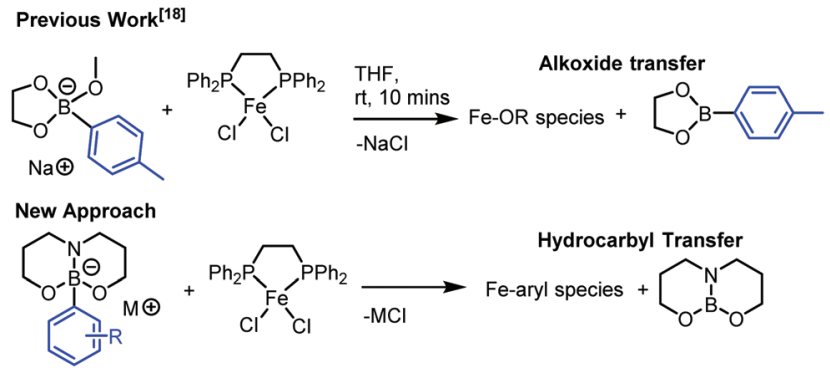

Fig. 1 Proposal to favour hydrocarbyl transmetallation over alkoxide transfer to iron from boronate reagents.

however these are non-productive in Fe catalysed SM couplings. ${ }^{12}$ Borates incorporating a trianionic 6,6-bicyclic chelate are rare, ${ }^{21}$ but are attractive as they will afford a reduction in ring strain in the conjugate 3-coordinate boronate ester formed post hydrocarbyl transfer relative to 5,5-bicyclic and 6,6,6-tricyclic (e.g. triolboronate) systems. This would facilitate the planarisation of the neutral 3-coordinate boronate ester byproduct and thus its stabilisation through increased $\pi$-orbital overlap, an outcome enhanced further by the greater multiple bond character present in B-NR $\mathrm{N}_{2}$ relative to $\mathrm{B}-\mathrm{OR}$; both factors were envisaged to enhance the nucleophilicity of the anionic hydrocarbyl-borate.

Combining 1.1 equiv. of dipropanolamine (which can be easily prepared on multi-gram scales from cheap, commercially available reagents) ${ }^{22}$ with phenylboronic acid (1 equiv.) in THF afforded the desired neutral boronate ester 1a within 10 minutes at ambient temperature. The poor solubility of $\mathbf{1 a}$ in THF allows for its isolation by filtration and subsequent recrystallisation from hot acetone affords analytically pure 1a in $89 \%$ yield $(9.74 \mathrm{~g}$ ) (Fig. 2). The rigid nature of the 6,6-bicyclic chelate is evident in the ${ }^{1} \mathrm{H}$ NMR spectra of 1a through the diastereotopic nature of the $\mathrm{CH}_{2}$ protons within the chelate backbone, a feature also observed in related 5,5-bicyclic systems. ${ }^{23}$ It is noteworthy that 5,5-bicyclic analogues demonstrate fluxional behaviour at temperatures above $40{ }^{\circ} \mathrm{C}$, whereas $1 \mathrm{a}$ is considerably more conformationally rigid, demonstrating no fluxional behaviour up to $110{ }^{\circ} \mathrm{C}$ (in $d_{6}$ DMSO), analogous to the extremely robust MIDA boronate esters. ${ }^{24}$ This simple esterification protocol can be extended to a number of aryl- or heteroarylboronic acids, affording neutral boronate esters $\mathbf{1 a}-\mathbf{1 q}$ in good to excellent isolated yields (97-72\%) (Fig. 2).

Generation of the anionic borates is simple as exemplified by the formation of $\mathbf{K}[2 \mathbf{a}]$ which can be achieved in quantitative yield via deprotonation of 1a with a variety of bases $(\mathrm{KH}$, ${ }^{t} \mathrm{BuOK}, \mathrm{KOMe}$ ) in anhydrous THF. ${ }^{25}$ The employment of $\mathrm{KOH}$ leads only to the recovery of neutral boronate ester, 1a. This observation correlates with the fact that $\mathbf{K}[2 \mathrm{a}]$ slowly hydrolyses to 1a (and presumably $\mathrm{KOH}$ ) with prolonged storage in the solid or solution state under air. With methods for the generation of the anionic borates in hand, we next focused upon calculating relative phenyl ion affinities (PhIAs) to assess the

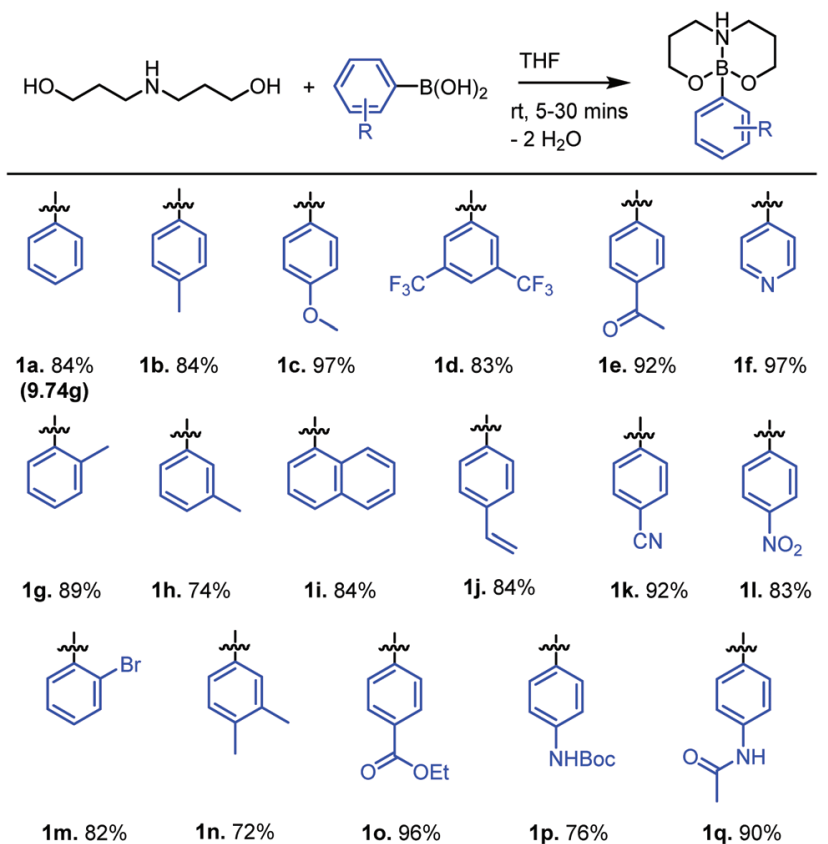

Fig. 2 Synthesis of dipropanolamine chelated neutral boronate esters 1a-1q.

relative nucleophilicity of $\mathbf{K}[\mathbf{2 a}]$ and other common borate anions. PhIAs were calculated from the isodesmic reactions between tetraphenylborate and the appropriate neutral boron Lewis acid (Table 1). This methodology is analogous to previous approaches for calculating hydride and chloride ion affinities (HIAs and CIAs) of boron Lewis acids, where calculations of HIA correlated well with hydride transfer reactivity. ${ }^{26,27}$ Analysis of the calculated PhIA values revealed neutral borane $\mathbf{3}$ to have a substantially lower PhIA (hence $\mathbf{K}[2 \mathbf{2}]$ will provide a better source of $\mathrm{Ph}^{-}$) than other common borate reagents tested (Table 1). The alleviation of ring strain in 3 relative to the 5,5-bicyclic analogue derived from diethanolamine (5,5-ONO, entry 4) and to a greater extent the 6,6,6-tricyclic containing triolborane (entry 1) does indeed have a considerable effect on PhIA and thus the energetics of aryl transfer.

The trends observed through calculated PhIAs were probed experimentally by phenyl ion transfer reactions. Initial studies commenced with $\mathbf{K}[2 \mathrm{2a}] / 3$ and boron reagents possessing considerably different calculated PhIAs. The addition of $\mathbf{K}[2 \mathbf{a}]$ to triolborane in THF resulted in slow dissolution of triolborane (which is poorly soluble in THF), with initial ${ }^{11} \mathrm{~B}$ NMR spectra (after $c a .10$ minutes at $20^{\circ} \mathrm{C}$ ) showing a mixture of $\mathbf{K}[2 \mathbf{a}]$ $\left(\delta_{11 \mathrm{~B}}=2.5\right)$ and a new species $\left(\delta_{11 \mathrm{~B}}=4.4\right)$ which is tentatively attributed to reversible Lewis adduct formation between $\mathbf{K}[\mathbf{2 a}]$ and triolborane, presumably by coordination of the $\mathrm{N}$ or $\mathrm{O}$ nucleophilic sites in $\mathbf{K}[\mathbf{2 a}]$ to the Lewis acidic boron centre of the triolborane. Nevertheless, heating this mixture at $60^{\circ} \mathrm{C}$ for $18 \mathrm{~h}$ resulted in complete disappearance of both of these signals, full dissolution of the triolborane and formation of 3 $\left(\delta_{11 \mathrm{~B}}=20.0\right)$ and $[\mathrm{Ph} \text {-triolborate }]^{-}\left(\delta_{11 \mathrm{~B}}=3.6\right)$ as the major 
Table 1 Relative phenyl ion affinities (PhIAs) of neutral boron Lewis acids derived from common arylborate reagents ${ }^{a}$

$\left[\mathrm{BPh}_{4}\right]^{-}+\mathrm{BR}_{3} \rightleftharpoons\left[\mathrm{BR}_{3} \mathrm{Ph}\right]^{-}+\mathrm{BPh}_{3}$

\begin{tabular}{|c|c|c|c|}
\hline Entry & Lewis acid & Abbreviation & $\operatorname{PhIA}^{a}\left(\mathrm{kcal} \mathrm{mol}^{-1}\right)$ \\
\hline 1 & & Triolborane & -22.8 \\
\hline 2 & $\mathrm{BF}_{3}$ & - & -16.3 \\
\hline 3 & $\mathrm{BPh}_{3}$ & - & 0.0 \\
\hline 4 & & $5,5-\mathrm{ONO}$ & +17.0 \\
\hline 5 & $\mathrm{~B}(\mathrm{OMe})_{3}$ & - & +22.7 \\
\hline 6 & & $\mathrm{~B}(\mathrm{Pin})\left({ }^{t} \mathrm{Bu}\right)$ & +23.2 \\
\hline 7 & & $\mathrm{~B}(\mathrm{Pin})\left({ }^{n} \mathrm{Bu}\right)$ & +23.9 \\
\hline 8 & & 3 (This work) & $+36.3(+31.3)^{b}$ \\
\hline
\end{tabular}

${ }^{a}$ PhIAs calculated at the M06-2X/6-311G+(d,p) level of theory with incorporation of a dichloromethane PCM solvent model. ${ }^{b}$ In parenthesis the PhIA is calculated using atomic coordinates from the solid state structure of $\mathbf{K}[\mathbf{2 a}]$.

species. The new boron species at $\delta_{11 \mathrm{~B}}=20$ was confirmed as the expected neutral 3-coordinate boron by-product of hydrocarbyl transmetallation via the independent synthesis and characterization of 3 from dipropanolamine and $\mathrm{Me}_{2} \mathrm{~S} \cdot \mathrm{BH}_{3}{ }^{25}$ The reaction of $\mathbf{K}[2 \mathrm{a}]$ with $\mathrm{Et}_{2} \mathrm{O}-\mathrm{BF}_{3}$ proceeded more rapidly with no starting materials observed after $<10 \mathrm{~min}$ at $20^{\circ} \mathrm{C}$ (by ${ }^{11} \mathrm{~B}$ NMR spectroscopy), instead 3 and $\left[\mathrm{PhBF}_{3}\right]^{-}$are the major species observed, along with an unidentified intermediate $\left(\delta_{11 \mathrm{~B}}=0.1\right)$ observed at short times which is fully consumed on heating to $60{ }^{\circ} \mathrm{C}$.

It is more significant in the context of this investigation to experimentally benchmark the PhIA of 3 against boron Lewis acids whose Ph-borate anions transmetallate to $\mathrm{Fe}$ (with or without additives). However, attempts to experimentally confirm the relative PhIA of $\mathrm{BPh}_{3}$ and 3 were frustrated by solubility issues (in THF and DCM) along with the formation of an intermediate $\left(\delta_{11 \mathrm{~B}}=0.8\right)$ that persisted even on heating to $60{ }^{\circ} \mathrm{C}$ for $18 \mathrm{~h}$, this species frustrated crystallisation attempts and is tentatively assigned to a Lewis adduct between $\mathbf{K}[2 \mathbf{a}]$ and $\mathrm{BPh}_{3}$. In contrast, combination of $\mathbf{K}[2 \mathbf{a}]$ and $\mathrm{B}(\mathrm{OMe})_{3}$ resulted in rapid phenyl transfer at $20{ }^{\circ} \mathrm{C}$ (with a short lived intermediate again observed, $\delta_{11 \mathrm{~B}}=3.1$ ), to ultimately form 3 and $\left[\mathrm{PhB}(\mathrm{OMe})_{3}\right]^{-}$, confirming the relative PhIA of 3 and $\mathrm{B}(\mathrm{OMe})_{3}$ (Scheme 1). The combination of $\mathbf{K}[2 \mathbf{a}]$ and $\mathrm{B}$ (Pin) $\left({ }^{n} \mathrm{Bu}\right)$ resulted in only a minor amount of 3 formed after $16 \mathrm{~h}$ at $60{ }^{\circ} \mathrm{C}$. We attribute the limited phenyl transfer to a kinetically slow process as opposed to an equilibrium favouring $\mathrm{B}(\mathrm{Pin})-\left({ }^{n} \mathrm{Bu}\right)$ and $\mathbf{K}[\mathbf{2 a}]$ as the reverse reaction of $\mathbf{3}$ with

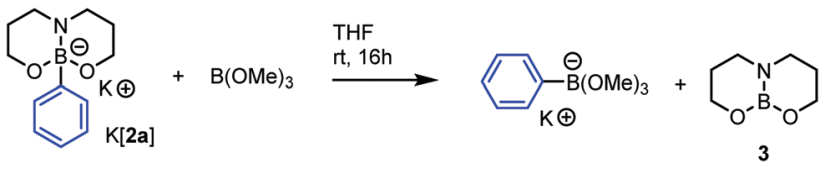

Scheme 1 Phenyl ion transfer reaction from $K[2 a]$ to trimethoxyborane.

$\left[\mathrm{PhB}(\mathrm{Pin})-\left({ }^{n} \mathrm{Bu}\right)\right]^{-}$resulted in minimal formation of $[2 \mathrm{a}]^{-}$after $16 \mathrm{~h}$ at $60^{\circ} \mathrm{C}$.

Encouraged by the calculated PhIA value of $\mathbf{3}$ and the stoichiometric phenyl ion transfer experiments, we moved on to probe whether high hydrocarbyl nucleophilicity in [2a]would translate to facile boron-to-iron hydrocarbyl transmetallation with common iron(II) (pre)catalysts. We began this investigation with the (pre)catalyst, $\left[\mathrm{Fe}(\mathrm{dppe}) \mathrm{Cl}_{2}\right]_{n} \mathbf{4}$ (dppe = 1,2-bis(diphenylphosphino)ethane) ( 4 was found by X-ray diffraction studies to exist as a $1 \mathrm{D}$ coordination polymer in the solid state on recrystallisation from THF). ${ }^{28}$ In situ generation of $\mathbf{K}[2 \mathbf{a}]$ with $\mathrm{KH}$ (1 equiv.) in anhydrous THF followed by the addition of 4 ( 0.5 equiv.) and dppe ( 0.5 equiv.) then agitation at ambient temperature led to no observable reaction (by ${ }^{11} \mathrm{~B}\left\{{ }^{1} \mathrm{H}\right\} \quad$ NMR spectroscopy, with $\mathbf{K}[2 \mathbf{a}]$ the only signal observed) after $1 \mathrm{~h}$. However, heating the reaction mixture for 10 minutes at $60{ }^{\circ} \mathrm{C}$ in THF (or in toluene) led to the pale green reaction mixture becoming deep red in colour. Analysis of the reaction mixture by ${ }^{1} \mathrm{H}$ NMR spectroscopy was uninformative, however the ${ }^{11} \mathrm{~B}\left\{{ }^{1} \mathrm{H}\right\}$ NMR spectra revealed the complete disappearance of the 4-coordinate signal of $\mathbf{K}[\mathbf{2 a}]$ and the presence of a single new boron containing species in the three-coordinate region at $\delta_{11 \mathrm{~B}} 23.9 \mathrm{ppm}$ attributed to $3 .^{29}$ Isolated samples of $\mathbf{K}[\mathbf{2 a}]$ generated from ${ }^{t} \mathrm{BuOK}$ or KOMe produced analogous outcomes, provided all protic by-products from boronate generation $\left({ }^{t} \mathrm{BuOH} / \mathrm{MeOH}\right)$ were removed prior to use due to their detrimental effect on these specific iron complexes. The requirement for raised temperatures for conversion of $\mathbf{K}[2 \mathrm{a}]$ to 3 on addition of $\mathbf{4} / \mathrm{dppe}$ is in contrast to the reaction of $\operatorname{Li}\left[(\mathrm{Ph}) \mathrm{B}\left(\mathrm{pin}\left({ }^{t} \mathrm{Bu}\right)\right](5)\right.$ with 4 (0.5 equiv. +0.5 equiv of dppe) which in our hands was found to react within minutes at ambient temperature in the absence of $\mathrm{MgBr}_{2}$ to produce ${ }^{t} \mathrm{BuBPin}$ (by ${ }^{11} \mathrm{~B}$ NMR spectroscopy). Thus whilst [2a] ${ }^{-}$is calculated to be thermodynamically a more nucleophilic source of $\mathrm{Ph}^{-}$than 5 it is kinetically slower to react by phenyl transfer with the Fe species present in solution under these conditions.

With the in situ ${ }^{11} \mathrm{~B}\left\{{ }^{1} \mathrm{H}\right\}$ NMR data being consistent with hydrocarbyl loss from [2a $]^{-}$we sought evidence for the formation of arylated iron species. Most notably the generation of significant quantities of biphenyl ( $c a .0 .5$ equiv.) post aryl transfer was confirmed by analysis of the reaction mixture by GC-MS against a calibrated internal standard, ${ }^{25}$ indicative of Fe-Ph species. ${ }^{14 b}$ Consumption of all $\mathbf{K}[2 \mathbf{a}]$ on addition of 0.5 equiv. of 4 (by ${ }^{11} \mathrm{~B}\left\{{ }^{1} \mathrm{H}\right\}$ NMR spectroscopy) suggests the transfer of two aryl equivalents to iron, although the transfer of just one aryl equivalent to Fe and formation of an adduct between an Fe species and a second equivalent of [2a] (which may not 
be observable in the ${ }^{11} \mathrm{~B}$ NMR spectra) is also feasible. We disfavour a reaction stoichiometry other than $2: 1$ as increasing the ratio of $\mathbf{K}[2 \mathrm{a}]:$ Fe from $2: 1$ to $3: 1$ and to $4: 1$ resulted in an increasing amount of $\mathbf{K}[2 \mathbf{a}]$ persisting in solution (by ${ }^{11} \mathrm{~B}$ NMR spectroscopy). Analogous outcomes were observed on combining $\mathbf{K}[\mathbf{2 c}]$ (or $\mathbf{K}[\mathbf{2 d}]$ ) and $\mathbf{4}$ in a $2: 1$ ratio, with significant biaryl formed in each case (by GC-MS versus an internal standard). Repeated efforts to isolate any Fe species from transmetallation to iron complexes with $\mathbf{K}[\mathbf{2 a} \mathbf{a}$ were unsuccessful in our hands.

$\left[\mathrm{Fe}(\mathrm{dpbz})_{2} \mathrm{Cl}_{2}\right], 6$ (0.5 equiv.) (dpbz = 1,2-bis(diphenylphosphino)benzene) reacted analogously with $\mathbf{K}[2 \mathbf{a}]$ or $\mathbf{K}[2 \mathbf{b}]$, with two equivalents of borate consumed per Fe centre (by ${ }^{11} \mathrm{~B}$ NMR spectroscopy) and significant biphenyl or bi-tolyl (ca. 0.5 equiv. by GC-MS) formed again indicating significant transmetallation from boron to iron. The previously reported iron(I) complex, $\left[\mathrm{Fe}(\mathrm{dpbz})_{2}(p\right.$-Tol) $] 7^{30}$ (Fig. 3) was observed from this reaction mixture by $\mathrm{X}$-band continuous-wave EPR measurements at $120 \mathrm{~K}$ further confirming successful boron to $\mathrm{Fe}$ transmetallation. The spectrum of 7 is in excellent agreement with previous X-band CW-EPR measurements obtained for 7
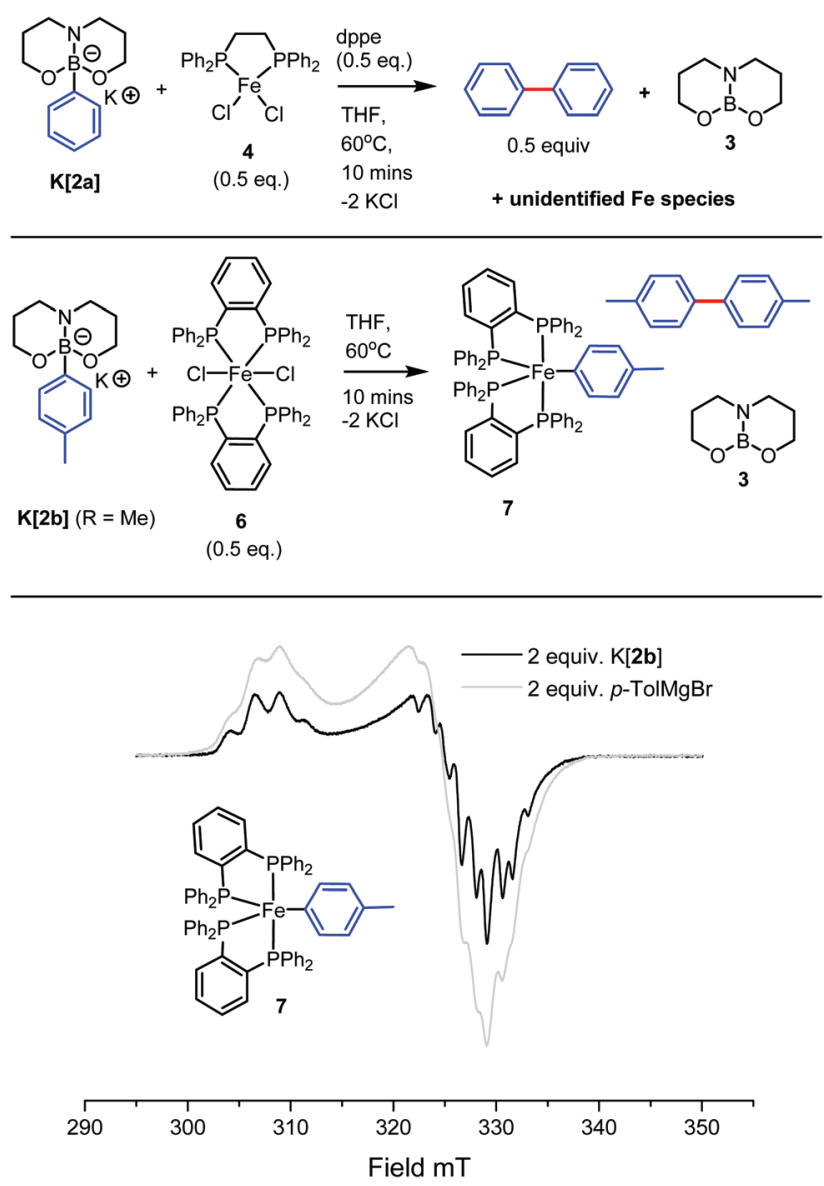

Fig. 3 Top, reaction of $K[2 \mathrm{a}]$ and 4 (0.5 equiv.). Middle, the formation of the Fe( 1 ) complex 7 from $\mathrm{K}[2 \mathrm{~b}]$ and 6 (0.5 equiv.). Bottom, comparison of the CW-EPR spectra recorded at $120 \mathrm{~K}$ of in situ generated 7 from either $\mathrm{K}[2 \mathrm{a}]$ (black) or $p$-TolMgBr (grey). by Bedford and co-workers ${ }^{30}$ and with an independently prepared sample of 7 obtained from the reaction of 6 with p-TolMgBr (2 equiv.) (Fig. 3). Whilst the presence of EPR and NMR spectroscopy silent Fe complexes cannot be precluded from these reactions the formation of significant quantities of the homocoupled biaryl compounds and the observation of 7 by EPR spectroscopy combined do confirm significant boron to iron hydrocarbyl transmetallation using [2x].

With boron-to-iron hydrocarbyl transmetallation confirmed we moved on to evaluating the efficiency of $\mathbf{K}[2 \mathbf{2}]$ in iron catalysed $\mathrm{Csp}^{2}-\mathrm{Csp}^{3} \mathrm{SM}$ cross-coupling. Employing $\mathbf{K}[\mathbf{2 a}]$ and 3-methoxybenzyl bromide in the presence of $\mathbf{4}+$ dppe (both at 10 mol\% loading) led to the complete consumption of 3-methoxybenzyl bromide and almost exclusive formation of 1,2-bis-(3-methoxyphenyl)ethane with only a very minor amount of heterocoupled product (by GC-MS). This observation is in contrast to the outcomes reported employing the ${ }^{t} \mathrm{BuLi}$ activated arylpinacol boronate esters, such as $\mathbf{5}$, or Grignard activated triorganoboranes, which under similar conditions, in the presence of magnesium or zinc additives led predominantly to heterocoupling products. ${ }^{14,15}$ Analogous homocoupling outcomes to that observed through the use of $\mathbf{K}$ [2a] were found in the employment of the lithium salt $\mathrm{Li}[\mathbf{2 a}$ ], hence the difference in reactivity between $\mathrm{M}[\mathbf{2 a}]$ and $\mathbf{5}$ is not cation derived. Furthermore, repeating the cross coupling reactions using $\mathrm{Li}[2 \mathrm{a}]$ with $\mathrm{MgBr}_{2}$ additive, led to homocoupling again being the dominant pathway.

Diarylzinc co-catalysts are used widely in Fe SM catalysis, but it is important to note that species formulated as $\operatorname{aryl}_{2} \mathrm{Zn}$ are actually often ionic zincates, and this can significantly impact reactivity in cross-coupling. ${ }^{31}$ For example, the previously reported attempted synthesis of $(p \text {-tol })_{2} \mathrm{Zn}$ led instead to the zincate $\left[\mathrm{Mg}(\mathrm{THF})_{4} \mathrm{Br}_{2}\left(\mathrm{Zn}(p \text {-tol })_{2}\right)_{2}\right]_{n}, \mathbf{8}$ (on recrystallisation, Scheme 2, inset). ${ }^{32}$ Using $10 \mathrm{~mol} \%$ of a stock solution of 8 (equating to a total of $0.08 \mathrm{mmol}$ of tolyl nucleophile) and $5 \mathrm{~mol} \% \mathbf{4} / \mathrm{dppe}$ resulted in the heterocoupling product from $\mathbf{K}$ [2a] and cyclo-heptylbromide being the major product (Scheme 2). However, the product distribution from this reaction is significantly less selective towards heterocoupling than cross coupling cycloheptylbromide using $\left[{ }^{t} \mathrm{BuB}(\mathrm{Pin}) \mathrm{Ar}\right]^{-}$(or $\left.\left[\mathrm{Ar}\left({ }^{\mathrm{i}} \mathrm{Pr}\right) \mathrm{BBN}\right]^{-}\right)$with magnesium or zinc additives. ${ }^{14,15}$ Repeating the coupling of cyclo-heptylbromide with $\mathbf{K}[\mathbf{2 a} \mathbf{a}$ in the absence of $\mathbf{8}$, with or without $\mathrm{MgBr}_{2}$ as an additive, led to no

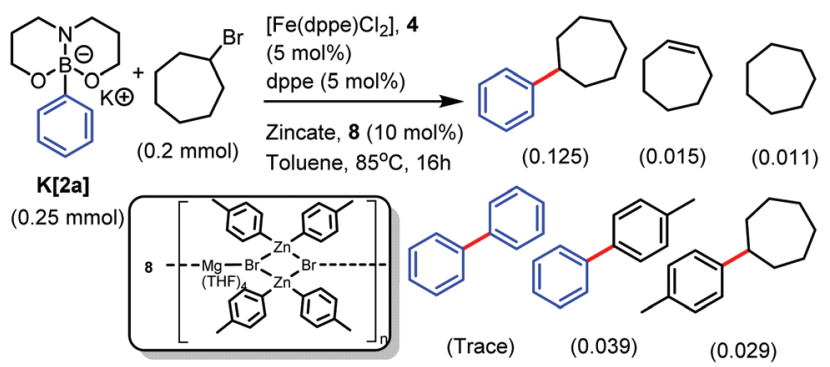

Scheme 2 Zincate mediated Fe catalysed SM cross coupling using $\mathrm{K}$ [2a]. 
heterocoupling product formation under a range of conditions. The omission of $\mathbf{4}$ also resulted in no heterocoupling confirming the importance of Fe under these conditions.

The disparity between magnesium and zinc additives led us to investigate the direct reaction between $\mathrm{MX}_{2}(\mathrm{M}=\mathrm{Zn}$ or $\mathrm{Mg}$, $\mathrm{X}=\mathrm{Br}$ or $\mathrm{Cl}$ ) and $\mathbf{K}\left[\mathbf{2 a}\right.$ ]. Combination of $\mathrm{MgBr}_{2}$ and $\mathbf{K}[\mathbf{2 a}]$ in THF resulted in no observable reaction at $20{ }^{\circ} \mathrm{C}$ and $60{ }^{\circ} \mathrm{C}$ (after $24 \mathrm{~h}$ by ${ }^{11} \mathrm{~B}$ NMR spectroscopy). In contrast, $\mathrm{K}[2 \mathrm{a}]$ reacts rapidly with $\mathrm{ZnCl}_{2}$ with complete consumption of $\mathbf{K}[\mathbf{2 a}]$ and formation of 3 as the only new observable boron containing product after $5 \mathrm{~h}$ in $\mathrm{THF}$ at $20^{\circ} \mathrm{C}$ or after $30 \mathrm{~min}$ in toluene at $60{ }^{\circ} \mathrm{C}$ (by ${ }^{11} \mathrm{~B}$ NMR spectroscopy). This is suggestive of transmetallation from boron in [2a] ${ }^{-}$to $\mathrm{ZnCl}_{2}$ but not to $\mathrm{MgBr}_{2}$, consistent with the disparate additive performance in Fe catalysed cross coupling reactions using $\mathbf{K}[2 \mathbf{2}]$. Related transmetallation from boron to $\mathrm{ZnCl}_{2}$ has been previously observed, e.g. using $\left[{ }^{\mathrm{S}} \mathrm{Bu}_{3} \mathrm{~B}(p\right.$-tolyl $\left.)\right][\mathrm{Mg}(\mathrm{solv}) \mathrm{Cl}],{ }^{15 b}$ which is a boron based aryl nucleophile also effective in Fe catalysed SM reactions. It is notable that less nucleophilic borates such as $\left[\mathrm{PhBF}_{3}\right]^{-}$and [PhBtriolborane $]^{-}$give no heterocoupling under Fe catalysed SM conditions even in the presence of zinc additives. ${ }^{12}$ In control reactions 2 equivalents of $\left[\mathrm{PhBF}_{3}\right]^{-}$(or $[\text { PhBtriolborane }]^{-}$) were heated in THF at $60{ }^{\circ} \mathrm{C}$ for $16 \mathrm{~h}$ with $\mathrm{ZnCl}_{2}$. Subsequent analysis of these reaction mixtures in $\mathrm{d}_{6}$ DMSO (in which all boron species, e.g., $\left[\mathrm{PhBY}_{3}\right]^{-}$and the conjugate neutral borane, are soluble) revealed no evidence for transmetallation to zinc with $\left[\mathrm{PhBF}_{3}\right]^{-}$(or $[\text {PhBtriolborane }]^{-}$) being the only major boron product observed (by ${ }^{11} \mathrm{~B}$ NMR spectroscopy).

\section{Conclusions}

In summary, neutral aryl- and heteroarylboronate esters incorporating a 6,6-bicyclic chelate and their corresponding anionic borates can be readily synthesised from the parent boronic acids. The novel borate species demonstrate enhanced hydrocarbyl nucleophilicities in comparison to other common arylborates, as assessed by PhIA calculations and stoichiometric phenyl ion transfer experiments. The new borates undergo additive-free, direct boron-to-iron hydrocarbyl transmetallations with simple bis-phosphine ligated iron(II) (pre)catalysts. However, the application of the new boronates to iron catalysed $\mathrm{Csp}^{2}-\mathrm{Csp}^{3}$ cross-coupling led predominantly to homocoupling in the absence of $\mathrm{Zn}$ additives, highlighting the inherent intricacies associated with iron-catalysed SuzukiMiyaura type $\mathrm{Csp}^{2}-\mathrm{Csp}^{3}$ cross-couplings. Presumably, the kinetics of aryl transfer to active Fe species (either direct or via aryl$\mathrm{Zn}$ species) has to be optimal to match other steps involved in the heterocoupling cycle and without zinc additives the transfer of aryl from boron in [2a] to key Fe species is non-optimal.

\section{Experimental}

\section{General experimental details}

Unless otherwise stated, all manipulations were carried out using standard Schlenk techniques under argon, or in an
MBraun UniLab glovebox, under an atmosphere of argon $\left(<0.1 \mathrm{ppm} \mathrm{O}_{2} / \mathrm{H}_{2} \mathrm{O}\right)$. Unless otherwise indicated, solvents were distilled from appropriate drying agents: tetrahydrofuran (potassium); toluene (potassium); $n$-hexane (NaK); and dichloromethane $\left(\mathrm{CaH}_{2}\right)$. Tetrahydrofuran and dichloromethane were stored over activated $3 \AA$ molecular sieves while toluene and $n$-hexane were stored over potassium mirrors. 3,3'-azanediylbis-(propan-1-ol), ${ }^{22}\left[\mathrm{Fe}(\mathrm{dppe}) \mathrm{Cl}_{2}\right],{ }^{33}\left[\mathrm{Fe}(\mathrm{dpbz})_{2} \mathrm{Cl}_{2}\right],{ }^{11}$ and $[\mathrm{Fe}-$ $(\mathrm{dpbz})_{2}(p$-Tol $\left.)\right]{ }^{30}$ were all prepared according to previously reported literature procedures. All other compounds were purchased from commercial sources and used as received. NMR spectra were recorded on Bruker AvanceIII-400, Bruker AvanceII-500 or Bruker Ascend-400 spectrometers. Chemical shifts are reported as dimensionless $\delta$ values and are frequency referenced relative to residual protio-impurities in the NMR solvents for ${ }^{1} \mathrm{H}$ and ${ }^{13} \mathrm{C}\left\{{ }^{1} \mathrm{H}\right\}$ respectively, while ${ }^{11} \mathrm{~B}\left\{{ }^{1} \mathrm{H}\right\},{ }^{19} \mathrm{~F}\left\{{ }^{1} \mathrm{H}\right\}$ and ${ }^{7} \mathrm{Li}$ shifts are referenced relative to external $\mathrm{BF}_{3}$-etherate, hexafluorobenzene and $\mathrm{LiCl}$, respectively. Coupling constants $J$ are given in Hertz $(\mathrm{Hz})$ as positive values regardless of their real individual signs. The multiplicity of the signals are indicated as "s", "d", "t" "pent", "sept" or "m" for singlet, doublet, triplet, pentet, septet or multiplet, respectively. High resolution mass spectra (HRMS) were recorded on a Waters QTOF mass spectrometer. GC-MS analysis was performed on an Agilent Technologies 7890A GC system equipped with an Agilent Technologies 5975C inert XL EI/CI MSD with triple axis detector. The column employed was an Agilent J\&W HP-5 ms ((5\%Phenyl)-methylpolysiloxane) of dimensions: length, $30 \mathrm{~m}$; internal diameter, $0.250 \mathrm{~mm}$; film, $0.25 \mu \mathrm{m}$. Microanalysis was performed by Mr Stephen Boyer at the London Metropolitan University microanalytical service. X-band CW-EPR spectra were recorded at $120 \mathrm{~K}$ on a Bruker EMXmicro spectrometer operating at $9.35 \mathrm{GHz}$ field modulation, $2 \mathrm{~mW}$ microwave power and equipped with a high sensitivity Bruker cavity (ER 4119HS).

\section{General procedure for the synthesis of $1 \mathrm{a}-1 \mathrm{q}$}

Under ambient conditions, with no additional precautions taken to exclude air or moisture, a round bottom flask was charged with 3,3'-azanediylbis(propan-1-ol) (1.1 equiv.) and tetrahydrofuran. To this stirred solution was added the appropriate boronic acid ( 1 equiv.) and the reaction mixture stirred at ambient temperature. Typically, the desired products $\mathbf{1 a - 1 q}$ began to deposit from solution after stirring for between 5 and 30 minutes, however in examples where this was not the case, stirring was continued at ambient temperature for $16 \mathrm{~h}$. Isolation of the insoluble material by filtration followed by washing with cold tetrahydrofuran typically afforded $\mathbf{1 a - 1 q}$ as colourless free-flowing solids of sufficient purity to be used without further purification. Alternatively, 1a-1q can be recrystallised from hot acetone.

10-phenyloctahydro-[1,3,2] oxazaborinino[2,3- $b][1,3,2]$ oxazaborinin-5-ium-10-uide $^{21}$ (1a): Prepared according to the general procedure. Phenylboronic acid $(6.10 \mathrm{~g}, 50.0 \mathrm{mmol})$ and 3,3'-azanediylbis(propan-1-ol) (7.33 g, $55.0 \mathrm{mmol}$ ) in tetrahydrofuran $(200 \mathrm{~mL})$ afforded $\mathbf{1 a}$ as a free-flowing white solid (9.74 g, 89\%). ${ }^{1} \mathrm{H}$ NMR (400 MHz, DMSO- $\left.d_{6}, 298 \mathrm{~K}\right): 7.39(2 \mathrm{H}$, 
$\mathrm{d}, J=6.7 \mathrm{~Hz}, o-\mathrm{CH}) ; 7.19(2 \mathrm{H}, \mathrm{t}, J=7.5 \mathrm{~Hz}, m-\mathrm{CH}) ; 7.09(1 \mathrm{H}, \mathrm{t}$, $J=7.5 \mathrm{~Hz}, p-\mathrm{CH}) ; 5.90(1 \mathrm{H}, \mathrm{bs}, \mathrm{NH}) ; 3.76-3.70\left(2 \mathrm{H}, \mathrm{m}, \mathrm{CH}_{2}\right)$; 3.50-3.44 (2H, m, CH $)$; 3.09-3.02 (2H, m, CH $\left.\mathrm{CH}_{2}\right) ; 2.86-2.80(2 \mathrm{H}$, $\left.\mathrm{m}, \mathrm{CH}_{2}\right)$; 1.81-1.72 (2H, m, $\left.\mathrm{CH}_{2}\right) ; 1.51-1.42 \mathrm{ppm}\left(2 \mathrm{H}, \mathrm{m}, \mathrm{CH}_{2}\right)$. ${ }^{13} \mathrm{C}\left\{{ }^{1} \mathrm{H}\right\}$ NMR (100 MHz, DMSO- $\left.d_{6}, 298 \mathrm{~K}\right): 131.8 ; 126.9 ; 125.5$; 59.7; 46.0; 24.3 ppm. ${ }^{11} \mathrm{~B}\left\{{ }^{1} \mathrm{H}\right\}$ NMR (128.4 MHz, DMSO- $d_{6}$, $298 \mathrm{~K}$ ): $3.2 \mathrm{ppm}$. HRMS (ESI) $\mathrm{m} / \mathrm{z}$ : calculated for $[\mathrm{M}+\mathrm{H}]^{+}$, $\mathrm{C}_{12} \mathrm{H}_{19} \mathrm{BNO}_{2}{ }^{+}, 220.1509$, found: 220.1516. Crystals suitable for $\mathrm{X}$-ray diffraction were grown by the slow evapouration of a concentrated acetone solution of $\mathbf{1 a}$ at ambient temperature.

See ESI $\uparrow$ for further details for $\mathbf{1 b} \mathbf{b} \mathbf{1 q}$ synthesised via the general procedure.

\section{General procedure for the synthesis of $\mathbf{M}[2 \mathrm{a}](\mathbf{M}=\mathbf{K}$ or $\mathbf{L i})$}

A flame dried Schlenk tube was charged with 1a (1 equiv.) and dried under vacuum for $c a .1 \mathrm{~h}$ prior to the addition of anhydrous THF or toluene (X mL) under an argon atmosphere. To this stirred suspension was added the appropriate base ( 1 equiv.) and the reaction mixture stirred at ambient temperature until the solution became homogeneous. Removal of the solvent generally afforded a pale residue which could be triturated with anhydrous $n$-hexane to afford $\mathrm{M}[2 \mathbf{a}](\mathrm{M}=\mathrm{K}$ or $\mathrm{Li})$ as a free-flowing white solid after isolation by filtration and drying under vacuum (see Table $\mathrm{S} 1 \dagger$ for isolated yields).

K[2a]: Prepared according to the general procedure. 1a (750.0 mg, $3.42 \mathrm{mmol}$ ) and $\mathrm{KH}(136.8 \mathrm{mg}, 3.42 \mathrm{mmol})$ in tetrahydrofuran $(10 \mathrm{~mL})$ afforded $\mathbf{K}[2 \mathrm{a}]$ as a free-flowing white solid $(862 \mathrm{mg}, 98 \%) .{ }^{1} \mathrm{H}$ NMR (400 MHz, THF- $\left.d_{8}, 298 \mathrm{~K}\right): 7.54(2 \mathrm{H}, \mathrm{d}$, $J=6.9 \mathrm{~Hz}, o-\mathrm{CH}) ; 7.09(2 \mathrm{H}, \mathrm{t}, J=7.2 \mathrm{~Hz}, m-\mathrm{CH}) ; 6.96(1 \mathrm{H}, \mathrm{t}, J=$ $7.5 \mathrm{~Hz}, \mathrm{p}-\mathrm{CH}) ; 3.61-3.56\left(2 \mathrm{H}, \mathrm{m}, \mathrm{CH}_{2}\right) ; 3.52-3.43\left(2 \mathrm{H}, \mathrm{m}, \mathrm{CH}_{2}\right)$; 3.34-3.25 (2H, m, CH $)$; 2.74-2.66 (2H, m, CH $\left.\mathrm{CH}_{2}\right) ; 1.88-1.75(2 \mathrm{H}$, $\left.\mathrm{m}, \mathrm{CH}_{2}\right) ; 1.36-1.26\left(2 \mathrm{H}, \mathrm{m}, \mathrm{CH}_{2}\right) \mathrm{ppm} .{ }^{13} \mathrm{C}\left\{{ }^{1} \mathrm{H}\right\}$ NMR $(100 \mathrm{MHz}$, THF- $\left.d_{8}, 298 \mathrm{~K}\right): 135.1 ; 127.1 ; 125.0 ; 62.6 ; 51.8 ; 31.1$ ppm. ${ }^{11} \mathrm{~B}$ $\left\{{ }^{1} \mathrm{H}\right\}$ NMR (128.4 MHz, THF- $\left.d_{8}, 298 \mathrm{~K}\right): 2.5 \mathrm{ppm}$. Anal Calcd for $\mathrm{C}_{12} \mathrm{H}_{18} \mathrm{BKNO}_{2}$ : C, 56.04; $\mathrm{H}, 6.66$; N, 5.45. Found: C, 55.84; $\mathrm{H}, 6.49 ; \mathrm{N}, 5.39$. Crystals suitable for X-ray diffraction were grown by the slow evaporation of a concentrated THF solution of $\mathbf{K}[2 \mathbf{a}]$ at ambient temperature.

\section{Computational details}

Calculations were performed using the Gaussian09 suite of programmes. ${ }^{34}$ Structures were pre-optimised at the HF/3-21G level followed by optimisation at the M06-2X/6-311G+(d,p) level $^{35}$ with inclusion of a PCM model for solvent correction (DCM). ${ }^{36}$ Structures were confirmed as minima by frequency analysis and the absence of imaginary frequencies.

\section{Acknowledgements}

We gratefully acknowledge the Royal Society (for the award of a University Research Fellowship for M. J. I.), the European Research Council under Framework 7 (J. J. D. grant agreement no. 305868), the Leverhulme Trust (E. R. C.) and the EPSRC (grant number EP/K039547/1) for funding. We also acknowledge the EPSRC UK National Service for Computational
Chemistry Software (NSCCS), the EPSRC UK National Electron Paramagnetic Resonance facility at the University of Manchester, Mr Daniel Sells for assistance with EPR measurements and Professor David Collison for helpful discussions.

\section{References}

1 N. Miyaura and A. Suzuki, J. Chem. Soc., Chem. Commun., 1979, 866-867.

2 N. Miyaura, K. Yamada and A. Suzuki, Tetrahedron Lett., 1979, 20, 3437-3440.

3 N. Miyaura and A. Suzuki, Chem. Rev., 1995, 95, 2457-2483.

4 For a review discussion the transmetallation in palladium catalysed Suzuki-Miyaura see: A. J. J. Lennox and G. C. LloydJones, Angew. Chem., Int. Ed., 2013, 52, 7362-7370.

5 E. Negishi, Hand-book of Organopalladium Chemistry for Organic Synthesis, Wiley, New York, 2002.

6 For recent reviews on Fe catalysed cross coupling see: (a) R. B. Bedford and P. B. Brenner, Top. Organomet. Chem., 2015, 50, 19-46; (b) O. L. Kuzmina, A. K. Steib, A. Moyeux, G. Cahiez and P. Knochel, Synthesis, 2015, 1696-1705; (c) E. Nakamura, T. Hatakeyama, S. Ito, K. Ishizuka, L. Ilies and M. Nakamura, Iron-Catalyzed Cross-Coupling Reactions, Org. React., 2013, 83(1), 1-210.

7 C. Bolm, J. Legros, J. Le Paih and L. Zani, Chem. Rev., 2004, 104, 6217-6254.

8 B. Plietker, Iron Catalysis in Organic Chemistry, Wiley-VCH, Weinheim, Germany, 2008.

9 (a) M. J. Ingleson and R. A. Layfield, Chem. Commun., 2012, 48, 3579-3589; (b) B. D. Sherry and A. Fürstner, Acc. Chem. Res., 2008, 41, 1500-1511.

10 For select recent articles in this area see: (a) S. L. Daifuku, M. H. Al-Afyouni, B. E. R. Snyder, J. L. Kneebone and M. L. Neidig, J. Am. Chem. Soc., 2014, 136, 9132-9143; (b) M. H. Al-Afyouni, K. L. Fillman, W. W. Brennessel and M. L. Neidig, J. Am. Chem. Soc., 2014, 136, 15457-15460; (c) Y. Liu, J. Xiao, L. Wang and L. Deng, Organometallics, 2015, 34, 599-605; (d) A. Hedstrom, Z. Izakian, I. Vreto, C.-J. Wallentin and P. O. Norrby, Chem. - Eur. J., 2015, 21, 5946-5953; (e) G. Bauer, M. D. Wodrich, R. Scopelliti and X. L. Hu, Organometallics, 2015, 34, 289-298; (f) J. A. Przyojski, K. P. Veggeberg, H. D. Arman and Z. J. Tonzetich, ACS Catal., 2015, 5, 5938-5946; $(g)$ D. Gaertner, A. L. Stein, S. Grupe, J. Arp and A. J. von Wangelin, Angew. Chem., Int. Ed., 2015, 54, 10545-10459; (h) O. M. Kuzmina, A. K. Steib, S. Fernandez, W. Boudout, J. T. Markiewicz and P. Knochel, Chem. - Eur. J., 2015, 8242-8249.

11 R. B. Bedford, E. Carter, P. M. Cosgwell, J. N. Harvey, N. J. Gower, M. F. Haddow, D. M. Murphy, E. C. Neeve and J. Nunn, Angew. Chem., Int. Ed., 2013, 52, 1285-1288.

12 R. B. Bedford, M. A. Hall, G. R. Hodges, M. Huwe and M. C. Wilkinson, Chem. Commun., 2009, 6430-6432.

13 For $\quad\left[(\text { alkenyl }) B(\operatorname{pin})\left({ }^{t} B u\right)\right]^{-}$see: T. Hashimoto, T. Hatakeyama and M. Nakamura, J. Org. Chem., 2012, 77, 1168-1173. 
14 For $\left[(\operatorname{aryl}) \mathrm{B}(\operatorname{pin})\left({ }^{t} \mathrm{Bu}\right)\right]^{-}$see: $(a)$ T. Hatakeyama, T. Hashimoto, Y. Kondo, Y. Fujiwara, H. Seike, H. Takaya, Y. Tamada, T. Ono and M. Nakamura, J. Am. Chem. Soc., 2010, 132, 10674-10676; (b) S. L. Daifuku, J. L. Kneebone, B. E. R. Snyder and M. L. Neidig, J. Am. Chem. Soc., 2015, 137, 11432-11444; (c) R. B. Bedford, P. B. Brenner, E. Carter, T. W. Carvell, P. M. Cogswell, T. Gallagher, J. N. Harvey, D. M. Murphy, E. C. Neeve, J. Nunn and D. R. Pye, Chem. - Eur. J., 2014, 20, 7935-7938; (d) R. B. Bedford, T. Gallagher, D. R. Pye and W. Savage, Synthesis, 2015, 1761-1765.

15 For $\left[\mathrm{R}_{3} \mathrm{BR}^{\prime}\right]^{-}$see: (a) T. Hatakeyama, T. Hashimoto, K. K. A. D. S. Kathriarachchi, T. Zenymo, H. Seike and M. Nakamura, Angew. Chem., Int. Ed., 2012, 51, 8834-8837; (b) R. B. Bedford, P. B. Brenner, E. Carter, J. Clifton, P. M. Cogswell, N. J. Gower, M. F. Haddow, J. N. Harvey, J. A. Kehl, D. M. Murphy, E. C. Neeve, M. L. Neidig, J. Nunn, B. E. R. Snyder and J. Taylor, Organometallics, 2014, 33, 5767-5780.

16 For a rare example of direct boron-to-iron transmetallation employing a low-coordinate iron hydride species see: Y. Yu, W. W. Brennessel and P. L. Holland, Organometallics, 2007, 26, 3217-3226.

17 For comments on the importance of boron-to-iron transmetallation see: J. A. Gladysz, R. B. Bedford, M. Fujita, F. P. Gabbaï, K. I. Goldberg, P. L. Holland, J. L. Kiplinger, M. J. Krische, J. Louie, C. C. Lu, J. R. Norton, M. A. Petrukhina, T. Ren, S. S. Stahl, T. D. Tilley, C. E. Webster, M. C. White and G. T. Whiteker, Organometallics, 2014, 33, 1505-1527.

18 J. J. Dunsford, I. A. Cade, K. L. Fillman, M. L. Neidig and M. J. Ingleson, Organometallics, 2014, 33, 370-377.

19 For an overview of boron transmetallating agents see: A. J. Lennox and G. C. Lloyd-Jones, Chem. Soc. Rev., 2014, 43, 412-443.

20 For specific examples using triolborates in palladium catalysis see: (a) Y. Yamamoto, M. Takizawa, X.-Q. Yu and N. Miyaura, Angew. Chem., Int. Ed., 2008, 47, 928-931; (b) S. Sakashita, M. Takizawa, J. Sugai, H. Ito and Y. Yamamoto, Org. Lett., 2013, 15, 4308-4311.

21 For one example of a neutral borane containing a 6,6-bicyclic chelate see: R. Csuk, H. Hönig and C. Romanin, Monatsh. Chem., 1982, 113, 1025-1035.

22 C. Granier and R. Guilard, Tetrahedron, 1995, 51, 11971208.

23 M. K. Reilly and S. D. Rychnovsky, Synlett, 2011, 23922396.

24 E. P. Gillis and M. D. Burke, J. Am. Chem. Soc., 2008, 130, 14084-14085.

25 See ESI. $\dagger$

26 (a) E. R. Clark, A. Del Grosso and M. J. Ingleson, Chem. - Eur. J., 2013, 19, 2462-2466; (b) E. R. Clark and M. J. Ingleson, Organometallics, 2013, 32, 67126717.

27 For neutral boranes see: M. T. Mock, R. G. Potter, D. M. Camaioni, J. Li, W. G. Dougherty, W. S. Kassel,
B. Twamley and D. L. DuBois, J. Am. Chem. Soc., 2009, 131, 14454-14465.

28 Crystals suitable for X-ray diffraction were obtained by heating a concentrated THF solution of 4 at $70{ }^{\circ} \mathrm{C}$ followed by slow cooling. See ESI $\dagger$ for the polymeric structure of 4 . During the course of this work an analogous structure was published see: D. Patel, A. Wooles, A. D. Cornish, L. Steven, E. S. Davies, D. J. Evans, J. McMaster, W. Lewis, A. J. Blake and S. T. Liddle, Dalton Trans., 2015, 44, 14159.

$29{ }^{11} \mathrm{~B}\left\{{ }^{1} \mathrm{H}\right\}$ NMR shifts of 3 vary over the range $20-24 \mathrm{ppm}$ due to presence of paramagnetic Fe complexes. In the absence of paramagnetic metal complexes it $\delta_{11 \mathrm{~B}}$ in $\mathrm{THF}$ is: 20.0 ppm.

30 C. J. Adams, R. B. Bedford, E. Carter, N. J. Gower, M. F. Haddow, J. N. Harvey, M. Huwe, M. Angeles-Carter, S. M. Mansell, C. Mendoza, D. M. Murphy, E. C. Neeve and J. Nunn, J. Am. Chem. Soc., 2012, 134, 10333-10336.

31 For the formation and role of zincates in cross-coupling see: (a) E. Hevia, J. Z. Chua, P. García-Álvarez, A. R. Kennedy and M. D. McCall, Proc. Natl. Acad. Sci. U. S. A., 2010, 107, 5294-5299; (b) L. Jin, C. Liu, J. Liu, F. Hu, Y. Lan, A. S. Batsanov, J. A. K. Howard, T. B. Marder and A. Lei, J. Am. Chem. Soc., 2009, 131, 16656-16657; (c) L. C. McCann and M. G. Organ, Angew. Chem., Int. Ed., 2014, 53, 4386-4389; (d) L. C. McCann, H. N. Hunter, J. A. C. Clyburne and M. G. Organ, Angew. Chem., Int. Ed., 2012, 51, 7024-7027; (e) T. D. Bluemke, W. Clegg, P. GarciaAlvarez, A. R. Kennedy, K. Koszinowski, M. D. McCall, L. Russo and E. Hevia, Chem. Sci., 2014, 5, 3552-3562; (f) R. B. Bedford, M. Huwe and M. C. Wilkinson, Chem. Commun., 2009, 600-602.

32 J. J. Dunsford, E. R. Clark and M. J. Ingleson, Angew. Chem., Int. Ed., 2015, 54, 5688-5692.

33 D. J. Evans, P. B. Hitchcock, G. J. Leigh, B. K. Nicholson, A. C. Niedwieski, F. S. Nunes and J. F. Soares, Inorg. Chim. Acta, 2001, 319, 147-158.

34 M. J. Frisch, G. W. Trucks, H. B. Schlegel, G. E. Scuseria, M. A. Robb, J. R. Cheeseman, G. Scalmani, V. Barone, B. Mennucci, G. A. Petersson, H. Nakatsuji, M. Caricato, X. Li, H. P. Hratchian, A. F. Izmaylov, J. Bloino, G. Zheng, J. L. Sonnenberg, M. Hada, M. Ehara, K. Toyota, R. Fukuda, J. Hasegawa, M. Ishida, T. Nakajima, Y. Honda, O. Kitao, H. Nakai, T. Vreven, J. A. Montgomery Jr., J. E. Peralta, F. Ogliaro, M. Bearpark, J. J. Heyd, E. Brothers, K. N. Kudin, V. N. Staroverov, R. Kobayashi, J. Normand, K. Raghavachari, A. Rendell, J. C. Burant, S. S. Iyengar, J. Tomasi, M. Cossi, N. Rega, J. M. Millam, M. Klene, J. E. Knox, J. B. Cross, V. Bakken, C. Adamo, J. Jaramillo, R. Gomperts, R. E. Stratmann, O. Yazyev, A. J. Austin, R. Cammi, C. Pomelli, J. W. Ochterski, R. L. Martin, K. Morokuma, V. G. Zakrzewski, G. A. Voth, P. Salvador, J. J. Dannenberg, S. Dapprich, A. D. Daniels, O. Farkas, J. B. Foresman, J. V. Ortiz, J. Cioslowski and D. J. Fox, GAUSSIAN 09 (Revision C1), Gaussian, Inc., Wallingford CT, 2009.

35 Y. Zhao and D. G. Truhlar, Theor. Chem. Acc., 2008, 120, 215. 36 http://comp.chem.umn.edu/info/DFT.htm. 